\title{
System of providing sustainability of tower cranes from overturn in extreme wind loads
}

\author{
Pavel Sorokin ${ }^{1}$, Alexey Mishin ${ }^{1}$, Vitaliy Antsev ${ }^{1}$, and Alexey Red'kin ${ }^{1, ~ *}$ \\ ${ }^{1}$ Tula State University, Tula, Russian Federation
}

\begin{abstract}
The article is devoted to the issues of ensuring stability of tower cranes from overturn. The development stages of devices for ensuring tower cranes safety are examined and their shortcomings are revealed. The system consisting of subsystems and drives is proposed and their interaction is presented. The article deals with a subsystem based on artificial intelligence methods. The neural network models of forecasting wind parameters are developed. The quality of work of neural network models is estimated. The ways of further topic development are suggested.
\end{abstract}

\section{Introduction}

The main requirement for the operation of tower cranes is to ensure their safety by maintaining their stability under adverse external influences. The overturning of tower cranes is a consequence of a set of unfavourable factors. Among the loads acting on tower cranes, the prevailing is the wind load.

The wind load is a random process. Gusts that occur with random repeatability with different energies increase the tipping point and cause additional loading of metal structures of tower cranes.

The possibility of occurrence of dangerous dynamic wind loads not only exists, which is confirmed by many years of observations, but there is a tendency for its growth.

The shortage of the standard security systems of tower cranes is lack of automatic control of the tower cranes stability in the period of extreme wind loads. The safety device provides only a warning about dangerous wind loads for the operator. When a dangerous wind speed is registered and an alarm goes off in the driver's cabin, he has a right to continue working, which is a failure to comply with safety requirements, which increases the likelihood of a tower crane being overturned. If the wind speed sensor fails or if it is intentionally disconnected by the operator, it is also impossible to ensure the stability of the tower crane against overturning.

The current direction is development of a security system for tower cranes with automatic control of their stability to prevent overturning due to extreme wind loads [1-3].

\footnotetext{
*Corresponding author: ra171171@yandex.ru
} 


\section{Block diagram of the tower crane stability system}

Advantages of the proposed stability system:

- the existing control diagram of the tower crane is equipped with additional stability system;

- for the first time the tower crane control algorithm includes the idea of forecasting wind loads based on artificial neural networks;

- the tower crane is minimally equipped with additional hardware and software.

The new stability system allows:

- to increase the level of safety by reducing accidents caused by the wind regime change;

- to reduce the cost of eliminating the consequences of tower cranes overturning (since accidents due to wind loads are excluded).

The proposed stability system is designed for stationary supporting and mobile rail tower cranes with a rotating and non-rotating tower with a beam arrow.

The stability system is based on the neural network and logical algorithms. A neural network algorithm is used to predict the direction and speed of the wind, and a logical algorithm is used to determine the dangerous wind speed (based on predicted values) in a gust and drive control in order to advance the tower crane to a safe position.

The tower crane stability system consists of a subsystem for collecting information about the wind and tower crane parameters, subsystems of neural network forecast and drive control. The block diagram is shown in Fig. 1.

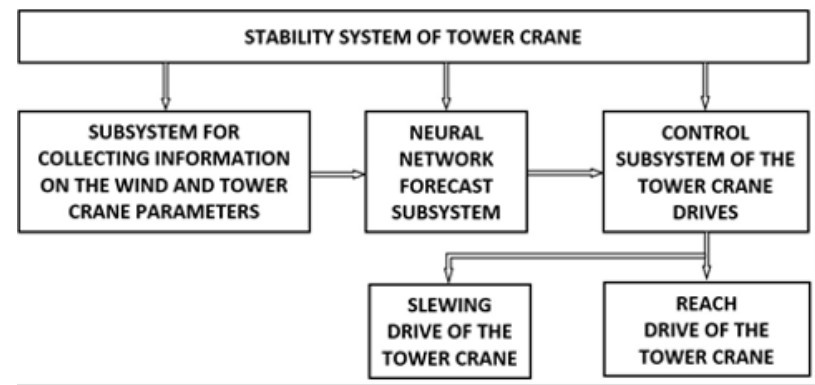

Fig. 1. Block diagram of the stability system of the tower crane.

The subsystem for collecting information on the wind and tower crane parameters consists of sensors, many of which are available in the existing load limiter - sensors of wind speed, arm position, hook lifting height, and hook outlet. In addition, the tower crane must be equipped with a wind direction sensor.

The neural network prediction subsystem is implemented on the basis of an expansion board with a neural network algorithm. The drive control subsystem of the tower crane is based on a programmable logic controller (hereinafter referred to as PLC).

\section{Neural network forecast models}

The condition of stability is issuance by the neural network forecast subsystem of a control signal and its processing by the control subsystem to trigger the drives before the critical tipping moment occurs from the gusts of wind.

The neural network forecasting model is a nonlinear autoregressive dependence of the following:

$$
x_{p}(t)=x(t-\Delta), \ldots x(t-N \Delta)
$$


where $x_{p}(t)$ is the predicted value; $x(t-\Delta), \ldots x(t-N \Delta)$ are the previous values measured in increments $\Delta$ (sampling frequency of the recorded values).

Forecasting is implemented on the basis of a neural network model with memory, which is the time delay line. The structural scheme for forecasting wind speed and direction is shown in Fig. 2.

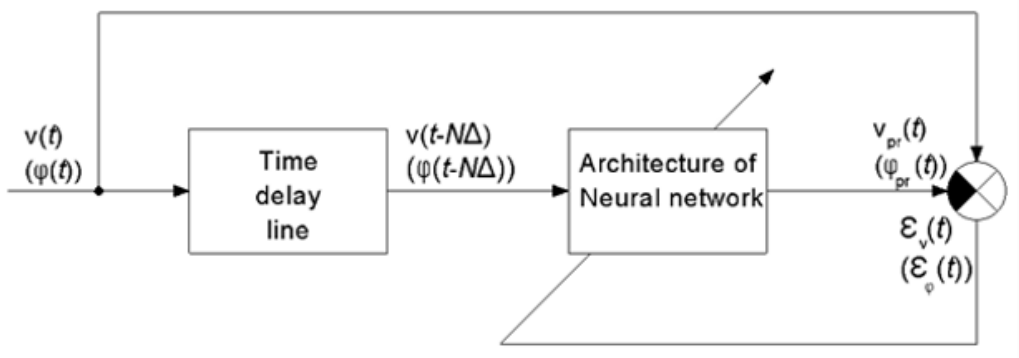

Fig. 2. The structural scheme of neural network for forecasting wind speed and direction.

Fig. 3 presents a generalized scheme of an artificial neural network (Direct Forward Propagation Network with a delay line [4,5], which is used to forecast wind parameters.

On basis of full-scale experiments conducted on a high-altitude meteorological mast, the data on the wind parameters change were obtained. The data were recorded at a sampling frequency of $1 \mathrm{~Hz}$.

In Fig. 4. the fragments of wind speed implementation are presented. The registered data are the basis for ANN modeling of speed and wind direction forecast, as well as of gust detection.

A series of computational experiments is based on the iterative simulation of ANN in the MATLAB software package. The simulation results for implementations are shown in Fig. 5.

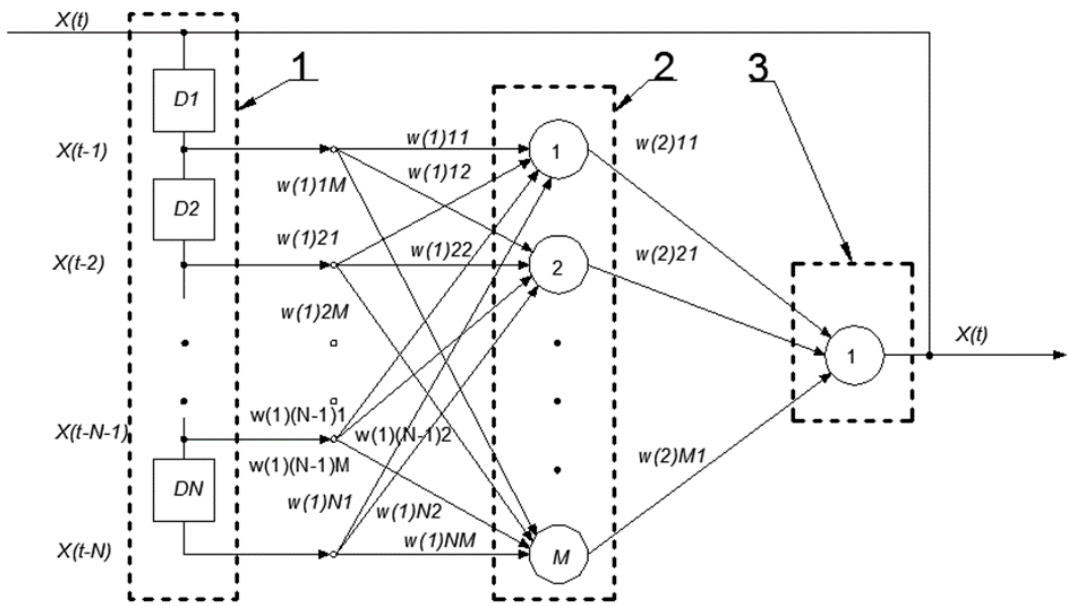

Fig. 3. The generalized scheme of a neural network model for forecasting wind parameters: 1 - delay line with taps; 2 - intermediate layer; 3 - output layer; $X(t)$ is the current (desired) value; $X$ $(\mathrm{t}-1) \ldots \mathrm{X}(\mathrm{t}-\mathrm{N})$ are the preceding values; $\mathrm{D} 1 \ldots \mathrm{DN}$ are elements of the delay line; $\mathrm{w}(1) 11 \ldots \mathrm{w}(1) \mathrm{NM}$ are the weight coefficients of the synaptic connections from the delay line to the hidden layer; $\mathrm{w}(2) 11$ ... w(2)M1 are weight coefficients of synaptic connections from the hidden layer to the output layer. 


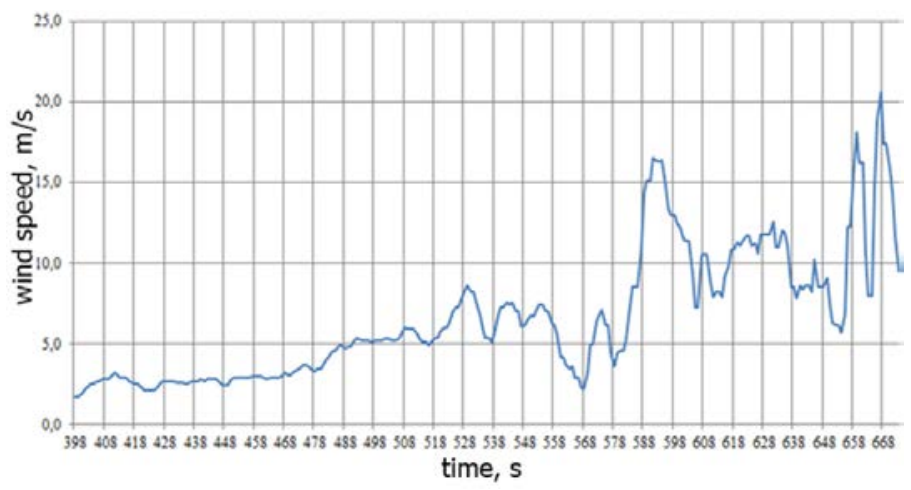

Fig. 4. Fragment of the wind speed change process.

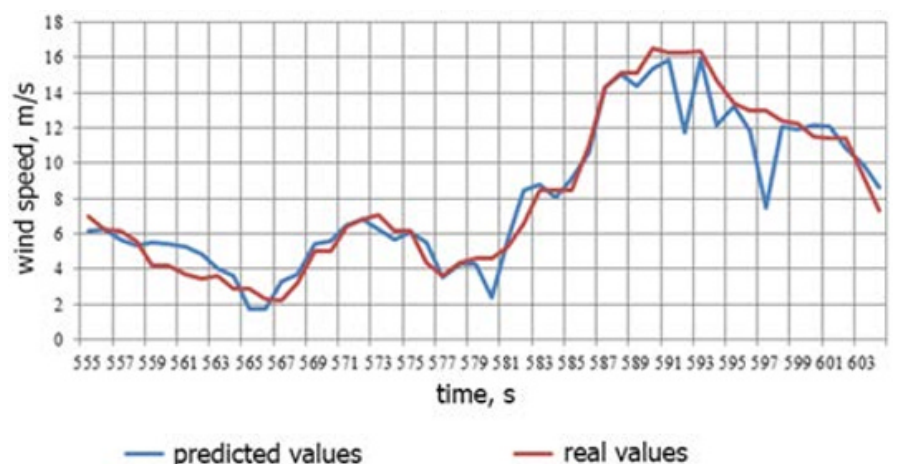

Fig. 5. Result of wind speed forecast (fragment).

Based on the results of the experiment and computer modeling, ANN is able to detect a dangerous gust of wind. This situation will be the starting point for the activation of the drive control subsystem.

To control the quality of operation ANN uses the criterion of minimum mean square error. The relationship between the predicted speed and the true wind speed is determined by regression analysis.

\section{Interaction of subsystems of neural network prediction and control of drives}

The PLC has an algorithm for the advance control of the pivot and/or change of departure drives. The algorithm is designed to output a control signal based on the neural network model (the neural network model program is stored in the expansion board memory) and the recorded values of the wind speed and direction sensors. The wind protection system is based on recording the wind speed and holding the mobile crane with anti-theft grips. When predicting a dangerous gust of wind and its direction, the PLC generates a control signal arriving at the pivot drive and/or the hook-change drive, to rotate the pivoting part of the tower crane in the direction of the predicted gust of wind. The stability system automatically intervenes in the operator's work only when forecasting a dangerous wind speed that exceeds the permissible value.

To prevent the stability system failure, the following actions are applicable:

- adaptation of neural network algorithms;

- planned preventive checks of neural network algorithms; 
- additional introduction to the stability system of the atmospheric pressure sensor at the design stage.

Introduction to the stability system of the atmospheric pressure sensor is due to the following reasons:

- if the wind speed sensor fails, it will be impossible to ensure the stability of the tower crane, since the neural network forecasting subsystem does not receive information about wind parameters;

- the failure of the stability system is eliminated, since the wind speed sensor failure (with a working air pressure sensor) ensures the stability of the tower crane.

The technical solution is based on the laws of atmospheric phenomena - before the occurrence of gusts there is a sudden change in atmospheric pressure.

The recording of the change in atmospheric pressure, activation of the alarm and determination of the failure of a particular sensor are implemented in the PLC software application in the CFC language. Also, the information about sensor failures is sent via the wireless link to the control room for the accumulation of failure statistics for all tower cranes of the construction site.

When checking neural network algorithms during the operation of a tower crane, it is possible to adapt it. This is due to the fact that during the operation of the tower crane, the database of wind parameters is constantly replenished and the computing power of the architecture of neural network algorithms laid down during their adapting may not be enough. The database should contain the values of the wind parameters over a long period of observation with different registration steps. Next, the neural network algorithms are adapted in the laboratory before the operation of the tower crane. Then the expansion board with the adapted algorithms is connected to the PLC, which is located in the control cabinet of the tower crane.

\section{Conclusion}

The proposed system for ensuring sustainability and its modernization make it possible to ensure the tower cranes stability under extreme wind loads. Continuous monitoring with extrapolation of parameters for the future state will allow the implementation of preemptive protection, which provides early detection of dangerous gusts of wind.

The condition of stability is the issue by the subsystem of the neural network forecast of the control signal and its processing by the drive control subsystem for the actuation of the pivot drive and/or the change-of-departure drive. The developed algorithms interfere with the regular work of the driver to ensure an emergency transfer of the tower crane to a safe position. Due to this, when turning, the windward area of the tower crane decreases, which leads to a decrease in pressure from the wind load, which will act at the following times.

The proposed stability system received a patent [6].

\section{References}

1. Z. Han, M. Hu, X. Song, R. Hao and X. Zheng, Tower Crane Effective Life Assessment Based on Tower Crane Fleet, Monitoring System, Information and Automation, v. 10-11 pp. 609-616 (2010)

2. Z. Sun, N. Hou and H. Xiang, Safety and serviceability assessment for high-rise tower crane to turbulent winds, Frontiers of Architecture and Civil Engineering in China, pp. 3-18 (2009) 
3. D. Voisin, G. Grillaud, C. Solliec, A. Beley-Sayettat, J.L. Berlaud and A. Miton, Wind tunnel test method to study out-of-service tower crane behavior in storm wind, Journal of Wind Engineering and Industrial Aerodynamics, v. 92 (7-8), pp. 687-697 (2004).

4. S. Haykin, Neural Networks and Learning Machines. (Third Ed. New Jersey: Pearson Education, 2008)

5. Y. Yu, Y. Tian, N. Feng and M. Lei, Research on Lifetime Prediction Method of Tower Crane Based on Back Propagation Neural Network, Advances in Electronic Commerce, Web Application and Communication, v. 148 (2), pp. 111-116 (2012)

6. P.A. Sorokin, A.V. Mishin, K.S. Khrjakov and A.V. Red'kin, Tower cranes rollover protection method. Patent application RU 2542850 of 27.02.2015. Federal Service for Intellectual Property, Patents and Trademarks, Moscow (2015) 